\title{
The mode of involvement and pattern of injury resulting from motorcycle road traffic accidents: data from a tertiary mission hospital in Ogbomoso, Nigeria
}

\author{
Durodola Adewumi Ojeniyi $M B B S, F W A C P,{ }^{1}$ Amole Isaac Olusayo $M B B S, F W A C P,{ }^{1}$ Adeniran Adenike $B S c$, \\ MBBS, FMCGP, ${ }^{1}$ Awotunde Olufemi Timothy MBBS, FMCGP. ${ }^{1}$
}

${ }^{1}$ Consultant Physician, Department of Family Medicine, Bowen University Teaching Hospital, Ogbomoso, Nigeria.

Address for Correspondence : Dr. Durodola, Adewumi Ojeniyi, Department of Family Medicine, Bowen University Teaching Hospital, Ogbomoso, Nigeria. Email: durodolamichael@ yahoo.com

\begin{abstract}
Background: The current increase in the use of motorcycles in Nigeria has been associated with an increased incidence rate of motorcycle road traffic accidents (MRTAs). Mode of involvement in MRTA differs; either as Pedestrian, Motorcyclist or as Passenger or Pillion rider. Aim and Objectives: To determine the prevalence of MRTA, mode of participation and the types and severities of injuries sustained by all those involved. Material and Method: A prospective, hospital-based descriptive study was conducted between September 2005 and June 2006. Eligible patients that presented to the Emergency Department were enrolled as subjects. Data was recorded in a structured recording schedule and analyzed using SPSS 11. Proportions were determined and statistics presented in tables. Results: There were 72 riders $(46.2 \%)$, 54passengers $(34.6 \%)$ and 30 pedestrians $(19.2 \%)$ seen during the study period. MRTA incidence rate was $49.5 \%$. The mean age was $34.33+16.48$ years and students were most affected $(21.2 \%)$. Sixty-six patients (42.3\%) each had injuries involving one and two body regions while 21 patients (13.5\%) had injuries involving three body regions. The most frequent injury severity score (ISS) was four (17.9\%). ISS was $\geq 5$ in 102 patients (65.4\%). Passengers were more likely to have ISS < 5 compared with riders and pedestrians. Injury to the left side occurred in $82.1 \%$ of the victims. Conclusion: Though injury pattern differs by mode of participation, injury severity was almost the same. More injuries occurred on the left side of the body and more passengers are likely to be injured on commercial motorcycles.
\end{abstract}

Keywords: Accidents, Body Region, Injury Severity, Motorcycle

\section{Introduction}

Road traffic accident (RTA) can be referred to as accident on a public highway where at least one of the traffic elements was moving [1]. A motorcycle is defined as a two wheeled vehicle, resembling a heavy bicycle, powered by an engine mounted between the wheels. One of the first commercial design, internal combustion motorcycle was manufactured in Germany in 1885 [2].

Road traffic injuries (RTI) are a major cause of misery, disability and death globally, with a disproportionate number occurring in developing countries [3]. Based on estimates that are at best conservative, Nigeria is a country with a serious and growing road crash problem which is among the worst in the world [3]. Deaths from

Manuscript received: $20^{\text {th }}$ Apr 2015

Reviewed: $4^{\text {th }}$ May 2015

Author Corrected: $14^{\text {th }}$ May 2015

Accepted for Publication: $30^{\text {th }}$ May 2015
RTI outnumber those recorded from many diseases of importance such as pneumonia, meningitis, tuberculosis and tetanus [4]. The World Health Organisation (WHO) has estimated many more childhood deaths from road crashes than from Human Immunodeficiency Virus (HIV) infection, although the prominence of communicable diseases in West Africa masks this relative epidemiologic significance of road traffic injuries [5].

World Health Day 2004, held on April 7, 2004 focused on road traffic injuries and measures to prevent them. One of such measures is to encourage the enforcement of road safety laws and preventive measures [6]. There has been an increase in the use of motorcycles in Nigeria over the last 10 years. With this increase in use is a corresponding increase in motorcycle road traffic accidents (MRTAs), some resulting in injuries which are disabling and others, in fatal injuries. 
The study site, Bowen University Teaching Hospital, Ogbomoso is situated on a Trunk A road and caters for many road traffic accident victims, some of them from motorcycle road traffic accidents. A review of the centre's record for prevalence rate of MRTAs showed a rise: rate of $10 \%$ in early 2004 , higher than a rate of $6.4 \%$ obtained in the same hospital in 1998 [7]. A question that needed to be asked was if the prevalence of MRTAs was really rising and the pattern of injuries sustained either as a Pedestrian, Motorcyclist or as a Passenger or Pillion rider. In order to ensure conformity with world-wide standards of injury description, a standardised injury scoring and classification system, the Abbreviated Injury Scale (AIS) [5,8] was used. This scale is the basis of most anatomic measures of injury severity.

\section{Study Area}

Ogbomoso is a town in South-western Nigeria. It is an inter-religious town situated about $100 \mathrm{~km}$ north of Ibadan, the capital of Oyo state, Nigeria. It is made up of 5 local government areas, with a projected population of five hundred and fifty five thousand, seven hundred and sixteen (555,716) [9]. Farming is a prominent occupation with the motorcycle being a common mode of transportation. There are also many artisans, traders and civil servants living in the area.

Baptist Medical Centre (now Bowen University Teaching Hospital, Ogbomoso) is a two hundred (200) bed mission hospital, founded in 1907. It provides primary, secondary and tertiary health care services.

\section{Ethical Consideration and Clearance}

Before the study commenced, ethical clearance was sought and obtained from the sub-committee on the ethics of human experimentation of Bowen University Teaching Hospital, Ogbomoso. Written consents were obtained from all patients with the understanding that their choice to be or not to be part of the study will not affect the quality of the care they were given. In the case of unconscious patients and children, consent was sought from relatives or guardians.

\section{Material and Method}

A prospective, hospital-based descriptive study was conducted between September 2005 and June 2006. All patients that presented to the Emergency Department at the Bowen University Teaching Hospital, Ogbomoso after being involved in motorcycle road traffic accident and that consented to be part of the study were enrolled as subjects. Patients withholding consent to be part of thestudy, unconscious patients without credible eye witness account of the accident, subjects brought in dead and victims of other forms of road traffic accidents were excluded from the study.

Data collected were recorded in a structured recording schedule and included: Name, age, sex, date and time of accident and presentation, mode of involvement and the use of motorcycle either for commercial or private use. In the cases of children and comatose patients, information was obtained from parents, guardians, relatives or eye witnesses as the case may be. When necessary, information supplied by the police and/or Federal Road Safety Corps officials was used.

Upon arrival to our emergency department, the patients were fully examined and type(s) of injury and body part(s) injured determined. For all patients, the severities of their injuries were also determined using the Injury Severity Score (ISS).

The ISS was calculated by following injury description, classification and grading as found in the Abbreviated Injury Scale (AIS) Dictionary, 1990 Revision (AIS-90) $[5,8]$. In the AIS dictionary, the body is divided into six body regions i.e.

1. Head and Neck region - includes injuries to the brain, skull and cervical spine.

2. Face region- includes injuries to the mouth, ears, eyes, nose and facial bones.

3. Chest region - including injuries to internal organs like diaphragm, and structures of the rib cage and thoracic spine.

4. Abdominal and Pelvic cavity content region including injuries to internal organs and lumber spine.

5. Extremities/ pelvic girdle /shoulder girdle region - includes sprains, fractures, dislocations, and amputations, except for the spinal column, skull and rib cage.

6. External region Injuries - including lacerations, contusions, abrasions, and burns, independent of their location on the body surface.

In the AIS, injuries were described and ranked on a scale of 1 to 6 , with 1 being minor, 2 moderate, 3 serious, 4 severe, 5 critical and 6 an un-survivable injury. These represented the threat to life of each injury described and not strictly an anatomical injury progression. The Injury Severity Score (ISS) is derived from the sum of the squares of the highest AIS grade in 
each of the 3 most severely injured body regions. The score ranges from 1 - 75. A patient with an AIS 6 in any body region is automatically assigned an ISS of 75 .
Data were analyzed by computer using the statistical package for social sciences (SPSS 11). Tables were employed for data presentation.

\section{Results}

During the nine months period of study between September 2005 and June 2006, a total of three hundred and fifteen patients (315) were seen in the emergency department after they were involved in any form of road traffic accident. In 156 patients, the injuries sustained were from MRTA. That gave motorcycle road traffic accident an incidence rate of $49.5 \%$ among all road traffic accidents. An average of 15.6 MRTA victims was seen monthly. There were seventy two riders $(46.2 \%)$, fifty four passengers $(34.6 \%)$ and thirty pedestrians $(19.2 \%)$.

Table 1: Socio-cultural Demographics

\begin{tabular}{|c|c|c|c|c|}
\hline Variables & Rider $(\%, \mathrm{~N}=72)$ & $\begin{array}{l}\text { Passenger } \\
(\%, \mathrm{~N}=54)\end{array}$ & $\begin{array}{l}\text { Pedestrian } \\
(\%, \mathrm{~N}=30)\end{array}$ & $\begin{array}{l}\text { Total } \\
(\%, N=156)\end{array}$ \\
\hline \multicolumn{5}{|c|}{ AGE RANGE (IN YEARS) } \\
\hline $0-9$ & $0(0.0)$ & $0(0.0)$ & $4(13.3)$ & $4(2.6)$ \\
\hline $10-19$ & $8(11.1)$ & $6(11.1)$ & $5(16.7)$ & $19(12.2)$ \\
\hline $20-29$ & $26(36.1)$ & $19(35.2)$ & $5(16.7)$ & $50(32.1)$ \\
\hline $30-39$ & $23(31.90$ & $11(20.4)$ & $1(3.3)$ & $35(22.4)$ \\
\hline $40-49$ & $6(8.3)$ & $6(11.1)$ & $2(6.7)$ & $14(9.0)$ \\
\hline $50-59$ & $7(9.7)$ & $7(13.0)$ & $2(6.7)$ & $16(10.3)$ \\
\hline $60-69$ & $1(1.4)$ & $5(9.3)$ & $4(13.3)$ & $10(6.4)$ \\
\hline $70-79$ & $1(1.4)$ & $0(0.0)$ & $5(16.7)$ & $6(3.8)$ \\
\hline $80-89$ & $0(0.0)$ & $0(0.0)$ & $2(6.7)$ & $2(1.3)$ \\
\hline \multicolumn{5}{|l|}{ SEX } \\
\hline Male & $72(100.0)$ & $34(63.0)$ & $13(43.3)$ & $119(76.3)$ \\
\hline Female & $0(0.0)$ & $20(37.0)$ & $17(56.7)$ & $37(23.7)$ \\
\hline \multicolumn{5}{|c|}{ OCCUPATION GROUP } \\
\hline Farmers & $16(22.2)$ & $4(7.4)$ & $8(26.7)$ & $28(17.9)$ \\
\hline Students & $8(11.1)$ & $16(29.6)$ & $9(30.0)$ & $33(21.2)$ \\
\hline Artisans & $13(18.1)$ & $5(9.3)$ & $0(0.0)$ & $18(11.5)$ \\
\hline Traders & $3(4.2)$ & $8(14.8)$ & $11(36.7)$ & $22(14.1)$ \\
\hline Civil servants & $4(5.6)$ & $7(13.0)$ & $2(6.7)$ & $13(8.3)$ \\
\hline Drivers & $2(2.8)$ & $3(5.6)$ & $0(0.0)$ & $5(3.2)$ \\
\hline Cyclists & $11(15.3)$ & $0(0.0)$ & $0(0.0)$ & $11(7.1)$ \\
\hline Teachers & $7(9.7)$ & $7(13.0)$ & $0(0.0)$ & $14(9.0)$ \\
\hline Others & $8(11.1)$ & $4(7.4)$ & $0(0.0)$ & $12(7.7)$ \\
\hline \multicolumn{5}{|c|}{ USE OF MOTOCYCLE } \\
\hline Commercial & $23(31.9)$ & $39(72.2)$ & $16(53.3)$ & $78(50)$ \\
\hline Private & $49(68.1)$ & $14(25.9)$ & $5(16.7)$ & $68(43.6)$ \\
\hline Unknown & $0(0.0)$ & $1(1.9)$ & $9(30.0)$ & $10(6.4)$ \\
\hline
\end{tabular}

The mean age was 34.33 years $(\mathrm{SD}=16.48)$. The youngest and oldest patients in this study were five and eighty-two years old respectively. The age group 20-29 years had the highest representation of 50 patients (32.1\%). There were eight teenage riders with the youngest being fifteen years old. The oldest rider was seventy years old. Most passengers were between twenty to forty years (55.6\% of passengers), just like the riders (68\% of riders). Eleven of the pedestrians (36.7\% of pedestrians) were either below ten years of age or above seventy years. 
One hundred and nineteen $(76.3 \%)$ of the patients were males. There was no female rider. Most pedestrians in this study were females (56.7\%). Students were most affected with $21.2 \%$ involvement rate followed by farmers $(17.9 \%)$. Eighteen patients were artisans $(11.5 \%)$, twenty-two were traders $(14.1 \%)$, thirteen were civil servants $(8.3 \%)$ and five were motor drivers $(3.2 \%)$. The commercial motorcyclist without any other form of occupation accounted for only $7.1 \%$ of the study group. Teachers and victims with other forms of occupation (apprentices, laborers, hunters, night guards etc.) accounted for $9 \%$ and $7.7 \%$ of the study group respectively.

\section{Table 2: Injury Severity Score}

\begin{tabular}{|c|c|c|c|c|}
\hline $\begin{array}{l}\text { INJURY SEVERITY SCORE } \\
\text { (ISS) }\end{array}$ & $\operatorname{Rider}(\%, \mathrm{~N}=72)$ & $\begin{array}{l}\text { Passenger } \\
(\%, \mathrm{~N}=54)\end{array}$ & $\begin{array}{l}\text { Pedestrian } \\
(\%, N=30)\end{array}$ & $\begin{array}{l}\text { Total } \\
(\%, \mathrm{~N}=156)\end{array}$ \\
\hline 1 & $7(9.7)$ & $10(18.5)$ & $1(3.3)$ & $18(11.5)$ \\
\hline 2 & $5(6.9)$ & $2(3.7)$ & $1(3.3)$ & $8(5.1)$ \\
\hline 4 & $10(13.9)$ & $12(22.2)$ & $6(20.0)$ & $28(17.9)$ \\
\hline 5 & $11(15.3)$ & $8(14.8)$ & $4(13.3)$ & $23(14.7)$ \\
\hline 6 & $2(2.8)$ & $2(3.7)$ & $0(0.0)$ & $4(2.6)$ \\
\hline 7 & $1(1.4)$ & $0(0.0)$ & $0(0.0)$ & $1(0.6)$ \\
\hline 8 & $3(4.2)$ & $1(1.9)$ & $0(0.0)$ & $4(2.6)$ \\
\hline 9 & $10(13.9)$ & $5(9.3)$ & $7(23.3)$ & $22(14.1)$ \\
\hline 10 & $8(11.1)$ & $7(13.0)$ & $5(16.7)$ & $20(12.8)$ \\
\hline 11 & $2(2.8)$ & $0(0.0)$ & $0(0.0)$ & $2(1.3)$ \\
\hline 12 & $1(1.4)$ & $0(0.0)$ & $1(3.3)$ & $2(1.3)$ \\
\hline 13 & $2(2.8)$ & $2(3.7)$ & $0(0.0)$ & $4(2.6)$ \\
\hline 14 & $3(4.2)$ & $1(1.9)$ & $1(3.3)$ & $5(3.2)$ \\
\hline 16 & $0(0.0)$ & $1(1.9)$ & $1(3.3)$ & $2(1.3)$ \\
\hline 17 & $3(4.2)$ & 1 (1.9) & $1(3.3)$ & $5(3.2)$ \\
\hline 18 & $0(0.0)$ & $0(0.0)$ & $1(3.3)$ & $1(0.6)$ \\
\hline 19 & $1(1.4)$ & $0(0.0)$ & $0(0.0)$ & $1(0.6)$ \\
\hline 24 & $1(1.4)$ & $0(0.0)$ & $0(0.0)$ & $1(0.6)$ \\
\hline 26 & $0(0.0)$ & $1(1.9)$ & $0(0.0)$ & $1(0.6)$ \\
\hline 29 & $1(1.4)$ & $0(0.0)$ & $0(0.0)$ & $1(0.6)$ \\
\hline 34 & $0(0.0)$ & 1 (1.9) & $0(0.0)$ & $1(0.6)$ \\
\hline 75 & $1(1.4)$ & $0(0.0)$ & $1(3.3)$ & $2(1.3)$ \\
\hline
\end{tabular}

Fifty percent of all the patients (78 patients) sustained their injuries from accidents involving motorcycles being used for commercial purposes. Sixty-eight patients $(43.6 \%)$ had injuries from motorcycles meant for private use. In accidents involving commercial motorcycles, thirty-nine passengers were injured. It is statistically significant that despite the fact that more private motorcycle riders were involved in accidents (68.1\% of riders), up to $72.2 \%$ of injured passengers sustained their injuries after taking commercial motorcycles. In ten patients $(6.4 \%)$, the use of the motorcycle was not known. Most of the patients in that sub -group were paediatric pedestrians.

\section{Injury Pattern}

The pattern of injury sustained were analyzed based on the type of injury, the body region involved and the injury severity score (ISS). Sixty patients $(38.5 \%)$ had injuries involving the head and neck region. The most frequent injury in the head and neck region was cerebral concussion (35\%). This was followed by cerebral contusions $(21.7 \%)$ and scalp lacerations $(15 \%)$. There were only three cases of cervical fractures (5\%). Forty-one patients $(26.3 \%)$ had injuries involving the face region. Most of the injuries to the face were abrasions and lacerations (51.2\%), followed by maxillofacial fractures $(19.5 \%)$. There were only four cases of injuries to the eye $(9.8 \%)$ and two cases of teeth fracture $(4.9 \%)$. 
Table 3: Injury Characteristics

\begin{tabular}{|c|c|c|c|c|}
\hline Variables & $\begin{array}{l}\text { Rider } \\
(\%, N=72)\end{array}$ & $\begin{array}{l}\text { Passenger } \\
(\%, N=54)\end{array}$ & $\begin{array}{l}\text { Pedestrian } \\
(\%, \mathrm{~N}=30)\end{array}$ & $\begin{array}{l}\text { Total } \\
(\%, N=156)\end{array}$ \\
\hline \multicolumn{5}{|l|}{ BODY REGION INJURED } \\
\hline Head, Neck And C-Spine & $34(47.2)$ & $11(20.4)$ & $15(50.0)$ & $60(38.5)$ \\
\hline Face( Ears, Eyes, Nose) & $25(34.7)$ & $9(16.7)$ & $7(23.3)$ & $41(26.3)$ \\
\hline Chest( Ribs, T-Spine) & $4(5.6)$ & $4(7.4)$ & $0(0.0)$ & $8(5.1)$ \\
\hline Abdominal\Pelvic ContentlL-Spine & $2(2.8)$ & $5(9.3)$ & $0(0.0)$ & $7(4.5)$ \\
\hline Extremities/Pelvic \&Shoulder Girdles & $42(58.3)$ & $41(75.9)$ & $16(53.3)$ & $99(63.5)$ \\
\hline lower extremity only & $33(45.8)$ & $30(55.6)$ & $9(30.0)$ & $72(46.2)$ \\
\hline upper extremity only & $4(5.6)$ & $11(20.4)$ & $5(16.7)$ & $20(12.8)$ \\
\hline both extremities & $5(6.9)$ & $0(0.0)$ & $2(6.7)$ & $7(4.5)$ \\
\hline External & $32(44.4)$ & $15(27.8)$ & $10(33.3)$ & $57(36.5)$ \\
\hline \multicolumn{5}{|c|}{ NUMBER OF BODY REGIONS INJURED } \\
\hline One & $25(34.7)$ & $26(48.1$ & $15(50.0)$ & $66(42.3)$ \\
\hline Two & $31(43.1)$ & $23(42.6)$ & $12(40.0)$ & $66(42.3)$ \\
\hline Three & $13(18.1)$ & $5(9.3)$ & $3(10.0)$ & $21(13.5)$ \\
\hline Four & $3(4.2)$ & $0(0.0)$ & $0(0.0)$ & $3(1.9)$ \\
\hline \multicolumn{5}{|l|}{ SIDE OF BODY INJURED } \\
\hline Right only & $10(13.9)$ & $12(22.2)$ & $6(20.0)$ & $28(17.9)$ \\
\hline Right $>$ Left & $1(1.4)$ & $3(5.6)$ & $3(10.0)$ & $7(4.5)$ \\
\hline Both sides equally & $29(40.3)$ & $16(29.6)$ & $13(43.3)$ & $58(37.2)$ \\
\hline Left $>$ Right & $2(2.8)$ & $1(1.9)$ & $1(3.3)$ & $4(2.6)$ \\
\hline Left only & $30(41.7)$ & $22(40.7)$ & $7(23.3)$ & $59(37.8)$ \\
\hline \multicolumn{5}{|l|}{ INJURY SEVERITY SCORE RANGE } \\
\hline ISS $<5$ & $22(30.6)$ & $24(44.4)$ & $8(26.7)$ & $54(34.6)$ \\
\hline ISS 5 and above & $50(69.4)$ & $30(55.6)$ & $22(73.3)$ & $102(65.4)$ \\
\hline
\end{tabular}

Only eight patients $(5.1 \%)$ had injuries involving the chest region. There was equal occurrence of chest lacerations, thoracic spine fractures and rib fractures (25\% each). A patient had a ruptured diaphragm. Seven patients $(4.5 \%)$ had injury to the abdominal and pelvic region. There were two cases each of ruptured spleen and abdominal wall lacerations. A patient sustained extensive scrotal injury with extension to the anus. Penetrating injury to the perineum led to bladder and urethral rupture in one patient.

The injuries considered under the extremities and girdle region included injuries to both upper and lower extremities, pelvic girdle and shoulder girdle. Ninety nine patients $(63.5 \%)$ had injuries involving the extremities and girdles region. This body region recorded the highest number of injuries. Multiple injuries were common. Abrasions and bruises accounted for $16.8 \%$ of the injuries sustained in this region. The most common long bone fracture was tibial fractures $(16.1 \%)$, followed by fibular fractures $(13.3 \%)$. Radial and ulnar fractures were the commonest upper limb fractures (3.5\% each).

If injuries to the lower and upper extremities were considered individually, it was apparent that the rate of injury occurrence was different. Injuries to the lower extremities occurred in seventy two patients $(72.7 \%$ of those injured in that region, $46.2 \%$ of all patients) and injuries to the upper extremities in twenty patients $(20.2 \%$ of those injured in that region, $12.8 \%$ of all patients). Both extremities were injured in seven patients $(7.1 \%)$.

Injuries to the external region occurred in fifty-seven patients $(36.5 \%)$. Injuries considered under external region included injuries to the skin like lacerations, contusions, abrasions, and burns. Once such injuries involved more than one body region and were the only injury, independent of their location on the body surface, they were considered as part of this region. 
Sixty-six patients (42.3\%) had injuries involving one body region. Another sixty-six patients (42.3\%) had injuries in two body regions while twenty-one patients (13.5\%) had injuries involving three body regions. Three patients (1.9\%) had injuries involving four body regions. Although more than half of the patients had injuries involving more than one body region, the severity differs from region to region. The most severely injured body region was the extremities and girdles in seventy patients (44.9\%), the head and neck region in forty-nine patients (31.4\%), the face region in nineteen patients (12.2\%), the external region in eight patients $(5.1 \%)$ and the abdomen and pelvic region in seven patients (4.5\%). There were more severe injuries in the chest region only in three patients (1.9\%). The most frequent injury severity score (ISS) was four (17.9\%). Two patients (1.3\%) had un-survivable injuries with maximum ISS of seventy five. The mean score was 8.38. One hundred and two patients $(65.4 \%)$ had ISS greater or equals to five. Passengers were more likely to have ISS less than five compared with riders and pedestrians.

Injury to the left side was the commonest. Fifty-nine patients (37.8\%) had injuries only on the left; twenty-eight patients (17.9\%) had injuries only on the right, fifty-eight patients (37.2\%) had injuries of equal severity on both sides of the body, seven patients $(4.5 \%)$ had injuries on the right greater than the left while four patients $(2.6 \%)$ had injuries on the left more than the right.

\section{Discussion}

The MRTA incidence rate of $49.5 \%$ was found in this study. That showed almost $800 \%$ increase in incidence rate in eight years compared to the $6.4 \%$ rate found in 1998 in the same centre [7]. The rate obtained portrays the rising trend in MRTA in the country reported before by previous authors [3,10-12], and the possibly reason is the general increase in the use of motorcycles for commercial purposes. However that the rate of $49.5 \%$ was still lower than $54.0 \%$ rate reported by Agnihotri and Joshi in Western Nepal [13] and a rate of $62.0 \%$ reported in Vietnam, Asian countries with wellestablished culture of motorcycle taxis.

Teenage riding seemed unpopular with only eight riders (11.1\% of riders) being between 10-19 years. In some resource-rich environment, younger riders are common [15-17]. This may be because of early access to motorcycles, while the reverse is the case in our environment. More than one-third of pedestrians (36.7\% of pedestrians) were either below ten years of age or above seventy years. The prominent involvement of paediatric patients in pedestrian MRTA has been documented [3,14]. The reasons for the ill-fated journey among the children with MCI were many. Travelling to and fro schools, as well as street hawking also put some children at risk. All the patients above age seventy except one rider were pedestrians. This involvement of older pedestrians in MRTAs may be due to poor vision and impaired agility.

Students were the most affected by MRTA in this study $(21.2 \%)$. These findings suggest the need for better transportation system for students in a bid to reduce the frequency of MRTA Although 50\% of the respondents sustained their injuries from commercial motorcycles, about $72.2 \%$ of all passengers injuries occurred in this group and not the riders. This is contrary to what should be expected, since the rider is in front and should bear the brunt of any frontal collision. A likely possibility is the fact that most passengers, especially of commercial motorcycles, are opportunistic riders and not able to maintain their balance well on a two wheeled vehicle and hence liable to fall off in motion.

More than half of the patients in this study (57.7\%) sustained injuries to more than one body region, the extremities and the head/neck region being the most affected in that order. Ninety-nine patients (63.5\%) injuries involved the extremities and girdles. Lower limb injuries accounted for $72.7 \%$ of such injuries. A very prominent injury among all mode of involvement was the fracture of the leg bones. Injuries to the face region were quite common among riders with $61 \%$ of such injuries occurring in them. This could be attributed to higher chances of facial impact in collision accidents or headlong falls from the bike.

Some protective clothing has been recommended for motorcyclists (riders and passengers). These include helmets to protect against head injury, goggles to protect the eyes, reflective clothing to make the riders more visible, but the use of protective clothing created and utilized solely to protect the limbs is not widespread [18-19]. Injuries to the external region occurring as sole injuries occurred in fifty seven patients. The injuries sustained included lacerations, abrasions, contusions and friction burns. Most of these 
injuries could have been protected with the use of protective clothings, which riders in Nigeria hardly ever wear.

In this study, a significant proportion of injuries $(82.1 \%)$ occurred in one form or another on the left side of the body. This occurrence is more noticeable among riders and passengers. Nigeria changed from using right-hand to left-hand drive vehicles in 1972 and now driving and riding is done on the right side of the road with on-coming traffic faced on the left. Therefore if a collision will occur in Nigeria with on-coming traffic, there are higher chances of injuries occurring on the left. Pedestrians are spared this movement restriction and had equal injury representation on both sides of the body.

The injury severity score (ISS) was less than five in about a third of the patients $(34.6 \%)$, and value of five and above in $65.4 \%$ of the patients. There was no statistical relationship between mode of involvement and ISS score above or below five. The means that whichever the mode of involvement, all were at risk of sustaining quite severe injuries from motorcycle road traffic accidents.

\section{Conclusion}

This study unveiled some basic but quite interesting findings about the prevalence of and the pattern of injury sustained from motorcycle road accidents in victims presenting in a secondary-care facility. Trauma remained a major problem in Nigeria with the rising trend in motorcycle accident contributing significantly to this. Though injury pattern differs by mode of participation, the likelihood of severe injury is almost the same. More injuries occurred on the left side of the body and more passengers are likely to be injured on commercial motorcycles. Road safety lectures should be incorporated into the educational system of the country from the nursery school level to educate all on the risks involved in motorcycle riding and how to avoid an accident. The government should provide mass transit facilities to reduce the tremendous transport pressure being exacted on the populace. More studies need to be carried out on the phenomenon of motorcycle road traffic accidents with the use of standardized injury scoring format to ensure proper review and auditing.

\section{Acknowledgment}

The author will like to acknowledge the staff of the Accident and Emergency department and all the Clinical House Staff of BUTH who assisted in data collection.

\section{Funding: Nil, Conflict of interest: None Permission of Ethical committee: Yes}

\section{References}

1. Hailemichael F, Suleiman M, Pauolos W. Magnitude and outcomes of road traffic accidents at Hospitals in Wolaita Zone, SNNPR, Ethiopia. BMC Research Notes. 2015;8:135. doi:10.1186/s13104-015-1094-Z.

2. Wikipedia contributors. Motorcycle history [Internet]. Wikipedia, The Free Encyclopedia; 2015 May 14, 18:04 UTC [cited 2015 May 28]. Available from:

http://en.wikipedia.org/w/index.php?title=Motorcycle_h istory\&oldid=662334783

3. Asogwa SE. Road Traffic Accidents in Nigeria: A handbook for all road users. 1st Edition. Enugu. SNAAP Press Ltd. 1999

4. Odero W, Garner P, Zwi A. Road traffic injuries in developing countries: a comprehensive review of epidemiological studies Trop Med Int Health. 1997 May;2(5):445-60.

5. Adesunkanmi ARK. A review of trauma scoring systems: uses and relevance to the developing countries. Nig Postgrad Med J 2000; 7: 75 - 84.

6. World Health Organization. World Health Day: Road safety is no accident! [Internet]. 2004 (cited 2015 May 27]. Available from: http://www.who.int/mediacentre/news/releases/2004/pr 24/en/

7. Oladiran IO. Epidemiology of road traffic accidents as seen in Baptist Medical Centre Ogbomoso.[Fell. thesis].Lagos: Nation Post-Grad Med College; 1998.

8. Linn S. The injury severity score-Importance and uses. Annals of Epid,1995 Nov; 5(6):440 - 46.

9. National Population Commission, Nigeria. Population distribution.[Internet] 2010 April[ cited 2015 Jan 24]. Available from: http://www.population.gov.ng/index.php/publications/1 
40-population-distribution-by-sex-state-lgas-andsenatorial-district-2006-census-priority-tables-vol-3

10. Ekwere PD. The clinical pattern of uro-genital trauma in a Nigerian hospital. The Nig Postgrad Med Jour, 2000;7(4): 171 - 76.

11. Solagberu BA, Ofoegbu CKP, Nasir AA, Ogundipe OK, Adekanye AO, Abdur-Rahman LO. Motorcycle injuries in a developing country and the vulnerability of riders, passengers, and pedestrians. Injury Prev 2006;12:266-8.

12. Oginni FO, Ugboko VI, Ogundipe O, Adegbehingbe BO. Motorcycle-related maxillofacial injuries among Nigerian intracity road users. J Oral Maxillofac Surg. 2006;64(1):56-62.

13. Agnihotri AK, Joshi HS. Pattern of road traffic injuries: one year hospital-based study in Western Nepal. Int J Inj Contr Saf Promot. 2006;13(2):128-30.

14. Nantulya VM, Reich MR. The neglected epidemic: road traffic injuries in developing countries. BMJ 2002;324:1139-41.
15. Reeder AI, Chalmers DJ, Langley JD Motorcycling attitudes and behaviours. I. 12 and 13 year old adolescents. J Paediatr Child Health. 1992;28(3):22530 .

16. Reeder AI, Chalmers DJ, Langley JD, Begg DJ. Motorcycling attitudes and behaviours. II. 14 and 15 year old adolescents. J Paediatr Child Health. 1992;28(5):387-94

17. Reeder AI, Chalmers DJ, Langley JD. Young onroad motorcyclists in New Zealand: age of licensure, unlicensed riding and motorcycle borrowing. Inj Prev. 1995;1(2):103-8

18. Lateef F. Riding motorcycles: is it a lower limb hazard? Singapore Med J. 2002;43(11):566-9.

19. Oluwadiya KS, Oginni LM, Olasinde AA, Fadiora SO. Motorcycle Limb Injuries in a Developing Country. West Afr J. Med. 2004; 23(1):42 - 7

\section{How to cite this article?}

Durodola Adewumi Ojeniyi, Amole Isaac Olusayo, Adeniran Adenike, Awotunde Olufemi Timothy. The mode of involvement and pattern of injury resulting from motorcycle road traffic accidents: data from a tertiary mission hospital in Ogbomoso, Nigeria. Int J Med Res Rev 2015;3(5):470-477. doi: 10.17511/ijmrr.2015.i5.091. 